Educa UMCH. Revista sobre Educación y Sociedad, 2020, 1(16), 5-221 https://doi.org/10.15366/Educa UMCH2019.17.3.001

\title{
Valores literarios en Los ríos profundos
}

Literary values in the deep rivers

Recibido el 17/ 09/ 2020. Revisión del 25/ 09/ 2020. Aceptado 27/09/2020

Humberto Collado Román

humbertocollado77@hotmail.com

Orcid: $0000-0001-6215-4329$

\section{Resumen}

Los valores literarios forman la mente y el corazón de los estudiantes, impactando a unos más que otros, según nuestra sensibilidad y el hábito en la lectura de los libros.

De esta forma aprendemos el sentir del alma de los hombres, mediante la literatura: "La lectura, aunque sea fragmentaria, de Homero, Shakespeare, Balzac, Dostoievski y Martí, puede enseñarnos, más sobre la condición humana que el resto de nuestro saber". (Espinoza, 1992).

En cambio, para Max Scheler los valores son aprendidos en una manera: emotiva, psicológica, lógica y del pensamiento. Siendo una de las características de los valores la jerarquía (éticos y estéticos), la cual gradúa los valores concebidos en forma a priori: "Valores sensibles: agradable- desagradable, gozar-sufrir. Valores vitales: salud, vejez, muerte. Valores espirituales: estéticos, jurídicos, gnoseológicos, etc. Valores religiosos: felicidad, desesperación, amor, entre otros; llegando a descubrir el odio, el amor, el acto moral". (como se citó en Morrero, 1913).

Como vemos los valores son importantes en la vida de la cultura de la sociedad y de los hombres. Siendo importante buscar el nexo entre la cooperación entre unos y otros.

Palabra clave: la literatura cumple importantes funciones en relación con los valores literarios, que se vincula con lo humano, lo social dentro del proceso enseñanzaaprendizaje.

\section{Summary}

Literary values shape the minds and hearts of students, impacting some more than others, according to our sensitivity and habit in reading books.

In this way we learn the feeling of the soul of men, through literature: "The reading, even fragmentary, of Homer, Shakespeare, Balzac, Dostoevsky and Martí, can teach us more about the human condition than the rest of our knowledge". (Espinoza, 1992). 
Instead, for Max Scheler values are learned in one way: emotional, psychological, logical and thoughtful. Being one of the characteristics of the values the hierarchy (ethical and aesthetic), which graduates the values conceived in a priori way: "Sensitive values: pleasant-unpleasant, enjoy-suffer. Vital values: health, old age, death. Spiritual values: aesthetic, legal, gnoseological, etc. Religious values: happiness, despair, love, among others; getting to discover hatred, love, the moral act". (Cited by Morrero, 1913).

As we see the values are important in the life of the culture of society and of men. It is important to find the nexus between the cooperation between one and the other.

Key word: literature fulfills important functions in relation to literary values, which is linked to the human, the social within the teaching-learning process.

\section{Introducción}

Hay diferentes modos de valorar de las personas, ya que se justifica la convicción de que los valores dependen de la persona que la valora. Hay pues ciertas paradojas entre los subjetivistas y objetivistas. Por tanto, podemos decir que los valores tienen que ser interpretados como que los valores valen y tienen significados importantes en las personas, produciéndose la interacción con su ambiente.

El destacado educador García Alzola plantea siete valores: "humano, social, estético, cultural, moral, intelectual y recreativo" (como se citó en Espinoza, 1992).

Los estudios valorativos en la novela Los ríos profundos de Arguedas J.M. nos conducen a centrarnos en considerar los valores literarios siguientes:

\section{Valor estético}

La literatura en su esencia está presidida por el sentido de la belleza, de allí que principalmente encierra valores estéticos. De tal manera que la lectura de un texto se convierte o nos brinda el goce estético. Además, estimula la reflexión frente a contenidos diversos de la cultura.

En cuanto al aprendizaje literario, según (Victorio, 1999). Sostiene que "el alumno entra en contacto con el uso del lenguaje expresivo o estético, al emplear algunas figuras literarias y así adquiere el gusto literario y el hábito de la lectura creadora".

\section{Valor humano}

El valor humano es importante en la literatura porque permite comprender al hombre con sus dificultades. El estudiante aprende a conocer más objetivamente al ser humano en sus motivaciones y reacciones ante las adversidades, ante sus debilidades y grandezas. Estas situaciones le permiten conocerse a sí mismo. 


\section{Valor social}

Facilita ponernos en contacto con las diferentes clases sociales, y nos permite arribar a juicios de valor sobre la convivencia humana en la sociedad: los conflictos, las luchas y las reivindicaciones entre los sectores sociales de una época a otra. En donde se observa el despotismo de los tiranos, las argucias de los demagogos, la indignidad de los ambiciosos y la humillación de los marginados.

\section{Valor cultural}

Se percibe con más notoriedad en la obra literaria porque está estrechamente relacionada con la vida sociocultural de una época. Es por eso que los estudiantes perciben favorablemente este valor al entrar en contacto con las manifestaciones culturales de una época en una determinada realidad. En consecuencia, en la épica, la novela, en el cuento, en el teatro podemos ver una sociedad con sus rasgos culturales, con sus costumbres, tradiciones, modas, lenguaje y folklore, etc.

\section{Valor ético-moral}

Permite distinguir objetivamente la conducta humana y observar lo positivo y negativo, examinando las diversas manifestaciones del bien y del mal. Estamos convencidos de que la literatura y los valores ejercen influencia en la conducta de los estudiantes y de nuestra sociedad.

\section{Valor intelectual}

Según (Victorio,1999) "El valor intelectual incentiva el pensamiento crítico, en donde los alumnos hacen comparaciones, inferencias, análisis y síntesis".

Por tanto, la lectura de obras literarias permite a los estudiantes encontrar nuevos secretos, mensajes, personajes, escenarios, medio ambiente, etc.

\section{Valor filosófico}

Estimula la meditación, la recapacitación, la abstracción y el pensamiento crítico. En donde se infiere y se busca las causas y ontologías, como el ser en la vida, la muerte, el amor, la guerra, las plagas, pestes, pandemias y las incomunicaciones humanas.

\section{Valor recreativo}

A través del valor recreativo se percibe la función del deleite, lo entretenido, divertido, ameno, gracioso, festivo, etc. En la lectura de las obras literarias, los estudiantes encuentran la recreación y el deleite. 


\section{El empleo de los valores literarios}

\section{El valor estético:}

\section{Figuras literarias en Los ríos profundos}

La obra Los ríos profundos posee figuras literarias que son recursos expresivos que consiste en usar connotativamente las palabras con una intención artística en la entonación, en la forma, en la función y en el sentido. Todo ello utiliza el autor para enriquecer su obra literaria. Entre las principales figuras literarias utilizadas por el escritor tenemos:

\section{a) La metáfora}

La metáfora es el sentido de la palabra que resulta de la identificación de un concepto con una imagen verbal. Ejemplo: mujer $=$ flor, vida $=$ río .

No siempre aparece el concepto o significado; pero sí la imagen en todo su esplendor creativo:

“- ¡Zumbayllu!, ¡zumbayllu!

Repetí muchas veces el nombre, mientras oí el zumbido del trompo". (Arguedas, 1983. p. 65).

Señala el autor que zumbayllu es la propagación de la música, que ocasiona el trompo al bailar. De manera que la palabra que tiene imagen verbal es la metáfora zumbayllu que al bailar en la explanada del suelo suscita notas musicales agradables y cantos al oído de los alumnos. Motivo por el cual se produce la aglomeración de los estudiantes en el patio del colegio.

"-El viejo ha clamado y me ha pedido perdón -dijo- pero sé que es un cocodrilo". (Arguedas, 1983. p. 14).

El autor señala que el viejo es un cocodrilo en el sentido traicionero.

Siendo la palabra con una imagen verbal, cocodrilo que no es de confiar, porque el personaje del viejo no solo es un fariseo sino también es un avaro.

“-Está usted en el sol, en la brisa, en el arco iris que brilla bajo los puentes, en mis sueños, en las páginas de mis libros, en el cantar de la alondra”. (Arguedas, 1983 p. 70).

Como se puede observar hay palabras: sol, brisa, arco iris, etc. Que hacen la función de metáfora porque compara a una mujer con una serie de elementos poéticos, que por su belleza están relacionados a la enamorada.

“-Si te pega te hará su oveja por todo el año". (Arguedas, 1983. p. 73). 
Educa UMCH. Revista sobre Educación y Sociedad, 2020, 1(16), 5-2̌2 https://doi.org/10.15366/Educa UMCH2019.17.3.001

Palacitos quiere decirle a Ernesto que, si se deja pegar por Rondinel, este lo hará su sirviente. (Cortez, 1993. p. 46).

\section{b) Comparación o símil}

Se limita a establecer una relación de semejanza o comparación de un objeto con otro que tenga cualidades similares. La diferencia con la metáfora es que en el símil se incluyen las palabras comparativas:

"-Se inclinó como un gusano que pudiera ser aplastado".

"A medida que baja al fondo del valle, el recién llegado se siente transparente, como un cristal en que el mundo vibra".

"-Odiaba a los forasteros como a las bandas de las langostas"

"-A esta hora debe estar temblando, llorando como un pajarito".

"-Como una flor de pisonay era su cara".

“-Los Morochucos vuelan en la estepa en caballos pequeños que corren como vicuñas”. (Arguedas, 1983. p. 33).

\section{c) La hipérbole}

Es la figura literaria que exagera las cosas aumentándolas o disminuyéndolas de un modo extraordinario:

"-Nosotros seguimos el viaje con una lentitud inagotable".

"Enloquecidas de entusiasmo, las mujeres cantaban cada vez más alto y más duro".

“-Nadie más alegre que ella”. “- ¡Ya no morirá nadie! (Arguedas, 1983. p. 33).

\section{d) La personificación}

Esta figura literaria consiste en atribuir cualidades propias de los seres animados, especialmente del hombre, a los objetos inanimados:

"-Papá - le dije- cada piedra habla. Esperemos un instante".

"La voz de la campana resurgía. También ha de ser el canto de María Angola".

"-La voz del arpa parecía brotar de la oscuridad que hay dentro de la caja".

"-Y de grandes ríos que cantan con la música más hermosa al chocar contra las piedras y las islas".

“-Eran los ojos del trompo, los cuatro ojos se hundían, como un líquido, en la dura esfera". (Arguedas, 1983. p. 65). 
Educa UMCH. Revista sobre Educación y Sociedad, 2020, 1(16), 5-2そ6 https://doi.org/10.15366/Educa UMCH2019.17.3.001

\section{e) Retrato}

Es la descripción física y moral de una persona:

"-Soy de Chalhuanca, joven. Su padre, el doctor, me honra. Puso su mano sobre mi hombro. Una bufanda de vicuña colgaba de su cuello; los botones de su camisa eran moradas. Tenía ojos claros, pero en su cara quemada parecían ojos de indio. Era idéntico a todos los amigos que mi padre había tenido en los pueblos". (Arguedas, 1983. p. 37).

\section{f) Paisaje}

Descripción de la belleza de la naturaleza:

"Se llama amank'ay a una flor silvestre, de corola amarilla y awancay al balanceo de las grandes aves. Awancay es volar planeando, mirando la profundidad. ¡Abancay! Debió ser un pueblo perdido entre bosques de pisonay y de árboles desconocidos, en un valle de maizales inmensos que llegaban hasta el río". (Arguedas, 1983. p. 34). 


\section{El valor humano en Los ríos profundos}

La novela Los ríos profundos posee un gran valor humano, que nos permite conocer al hombre en su forma más objetiva, es decir, conocer sus debilidades y grandezas:

"Los hacendados de los pueblos pequeños contribuyen con grandes vasijas de chicha y pailas de picantes para las faenas comunales. En las fiestas salen a las calles y a las plazas, a cantar huaynos en coro y a bailar. Caminan de diario, con polaina vieja, vestidos de diablo fuerte o casinete, y una bufanda de vicuña o de alpaca en el cuello. Montan en caballos de paso, llevan espuelas de bronce. Montan en caballos de paso, llevan espuelas de bronce, siempre, sobre la montura, un pellón de cuero de oveja. Vigilan a los indios cara a cara, y cuando quieren más de lo que comúnmente se cree que es lo justo, les rajan el rostro o le llevan a puntapiés hasta la cárcel, ellos mismos”. (Arguedas, 1983. p. 40).

En toda la obra literaria hay una constante preocupación de José María Arguedas por tratar la problemática del hombre andino, de aquel hombre aborigen, cuyos antecedentes es una raza milenaria que forjara un gran imperio, ahora vilmente subyugados.

Ernesto comparte sus sufrimientos de los colonos, de los indios que pertenecen a las haciendas, y se identifica con sus problemas, siente igual que ellos el sufrimiento y asume su defensa y denuncia con entera franqueza la injusticia:

\footnotetext{
“¡Por diez oroyas! Ya están llegando - dijo-

¿Quiénes?, le pregunté

-Los colonos, pues, de quince haciendas. ¿No sabes, niño?

Anoche, un guardia ha muerto.

Una oroya cortó con su sable, dice a golpes, cuando los colonos estaban pasando... ocho, dicen cayeron al Pachachaca.

Han querido acorralaralos colonosa la orilladelrio...

Dicen que todos los guardias van a ir a ahora con metralla para atajar a los colonos en el camino

¿Quién manda la peste? ¡Es maldición!

"iInglesia, inglesia; misa, Padrecito!”,

están gritando, dice, los colonos.

Ya no hay salvación, pues, misa grande

quieren, del padre grande de Abancay.

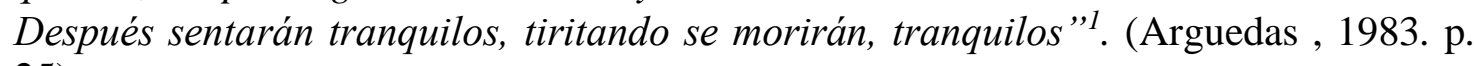
25).
}

Esta herencia de dominación y opresión hacia los colonos se plasma en Los ríos profundos. El blanco está representado por los terratenientes, el padre Linares, autoridad del catolicismo, perteneciente al mundo blanco dominante. Los colonos 
Educa UMCH. Revista sobre Educación y Sociedad, 2020, 1(16), 5-2飞8 https://doi.org/10.15366/Educa UMCH2019.17.3.001

y todos los explotados son los dominados. De ellos Ernesto se conduele y comparte sus sufrimientos. Allí radica fundamentalmente el valor humano.

\section{El valor social}

La novela Los ríos profundos es eminentemente social, por tanto, tiene un inmenso valor dentro de la obra.

José María Arguedas nos hace ver con realismo la problemática social del mundo andino, así se observa que la organización socioeconómica está dividida en dos clases sociales: la clase terrateniente es la clase explotadora y dominante, mientras que los campesinos colonos sin tierra forman la parte de la clase explotada y dominada.

"La casa de esos hacendados es bien conocida por los indios. Duermen en catres de bronce, con techo de varillas doradas. La casa tiene un patio y un corral grande, un corredor, una despensa, un troje, una sala amueblada con barras y sillones antiguos de madera; y la cocina, que siempre está lejos, al otro lado del patio, porque allí comen los peones...

La casa-hacienda aparecía rodeada de muros blanqueados. Una reja de acera protegía el arco de entrada.

El patrón y su familia vivían como perdidos en la inmensa villa. Un callejón ancho comunicaba la residencia del patrón con la fábrica y el caserío donde viven los indios colonos...

Los dueños de las haciendas sólo venían al colegio a visitar al Padre Director. Cruzaban el patio y sin mirar a nadie.

- ¡El dueño de Auquibamba! -decían los internos.

- ¡El dueño de Pati!

- ¡El dueño de Yaca!

$Y$ parecían que nombraban a las grandes estrellas.

El Padre Director iba a celebrar misa para ellos en las capillas de las haciendas" (Arguedas, 1983. p. 42).

También se observa, en Los ríos profundos, la toma de conciencia y la lucha de clases. El indio no es aquel ser pintoresco, sumiso, callado, sino aquel que protesta y que lucha por su bienestar. El personaje que sintetiza esta encarnación es precisamente Ernesto, es un ser solidario, leal a su conciencia moral y al mundo cultural que ha elegido. Se define así mismo abrazar al pongo e identificarse con su causa social. También, al sirviente como un ser digno:

"El indio cargó los bultos de mi padre y el mío. Yo lo había examinado atentamente porque suponía que era el pongo (indio de hacienda que sirve gratuitamente). El pantalón, mиy ceñido, sólo le abrigaba hasta las rodillas. 
Educa UMCH. Revista sobre Educación y Sociedad, 2020, 1(16), 5-229 https://doi.org/10.15366/Educa UMCH2019.17.3.001

Estaba descalzo; sus piernas desnudas mostraban los músculos en paquetes duros que brillaban...nonosmiró.

-Taita -le dije en quechua al indio-. ¿Tú eres cuzqueño?

-Manan-contestó-, de la hacienda.

Tenía un poncho raído, muy corto. Se inclinó y pidió licencia para irse. Se inclinó como un gusano que pudiera ser aplastado...

Me acerqué al pongo y me despedí de él. No se asombró tanto.

Lo abracé sin estrecharlo. Iba a sonreír, pero gimoteó, exclamando en quechua: “iNiñito, ya te estás yendo! ¡Ya te estás yendo!”(Arguedas, 1983. p. 25).

Como se puede observar, Ernesto es el prototipo del indio que lucha por sus ideales hasta las últimas consecuencias, porque sigue la causa india, buscando la integración entre el mundo blanco e indio.

\section{El valor cultural}

La novela Los ríos profundos contiene un inmensurable valor cultural.

José María Arguedas escribió con mucha pasión diferentes aspectos culturales, tales como costumbres de los pueblos andinos, las fiestas religiosas, canciones en quechua, mitos, leyendas, etc.

“... ;Estamos en el Cuzco! Le dije.

Mi padre me había hablado de su ciudad nativa, de los palacios y templos, y de las plazas, durante los viajes que hicimos, cruzando el Perú de los Andes de oriente a occidente y de sur a norte.

Ya había creído en esos viajes.

Eran más grandes y extraños de cuanto había imaginado las piedras del muro incaico... Me acordé, entonces, de las canciones quechuas que repiten una frase patética constante: "Yawar mayu”, río de sangre; "yawar unu”, agua sangrienta; "puk'tik yawar k'ocha", lago de sangre que hierve; "yawar wek'e”, lágrimas de sangre. ¿Acaso no podría decirse "yawar rumi”, piedra de sangre, o "puk'tik yawar rumi", piedra de sangre hirviente? Era estático el muro, pero hervía por todas sus líneas y la superficie era cambiante, como la de los ríos en el verano, que tienen una cima así, hacía el centro del caudal, que es la zona temible, la más poderosa. Los indios llaman "yawar mayu” a esos ríos turbios, porque muestran con el sol un brillo en movimiento, semejante al de la sangre. También llaman "yawarmayu” al tiempo violento delas danzas guerreras, al momento en que los bailarines luchan. 
- ¡Puk'tik yawar rumi! -exclamó frente al muro, en voz alta.

Mi padre llegó en ese instante a la esquina. Oyó mi voz y avanzó por la calle angosta... nos iremos mañana... pero yo soy cristiano, y tendremos que oír misa, al amanecer, con el viejo, en la catedral. Nos iremos enseguida. No veníamos al Cuzco; estamos de paso a Abancay. Seguiremos viaje. Éste es el palacio de Inca Roca. La plaza de armas está cerca. Vamos despacio. Iremos también a ver el templo de Acllahuasi (era un convento donde estaban las vírgenes escogidas de la nobleza imperial, dedicadas al servicio del sol y del Inca).

El Cuzco está igual. Siguen orinando aquí los borrachos y los transeúntes. Más tarde habrá aqui otras fetideces...”. (Arguedas, 1983. p. 14).

Como vemos José María Arguedas es un gran conocedor de todo cuanto existe en el universo andino, no solo como etnólogo, antropólogo, maestro, sino como un gran protagonista auténtico de esos lares queridos.

Además, merece destacar que en Los ríos profundos el escenario abarca más allá de las fronteras de la sierra peruana y nos hace ver la vida citadina en especial de la ciudad del Cusco y su paso a Abancay. De esta manera, presenta el contraste entre la vida rural y urbana. Se ve la diferencia en la vestimenta, la vivienda y la música.

En el aspecto cultural Arguedas es más amplio en Los ríos profundos a diferencia de sus otras obras. Razón suficiente tiene el crítico Roland Forgues cuando afirma lo siguiente: "En el ámbito cultural, la convivencia de las dos comunidades étnicas, blanca e india, y el roce de dos culturas, española e indígena, origina a su vez un poderoso proceso de mestizaje, aculturación y sincretismo religioso en el que José María Arguedas parece fundar toda su esperanza para la formación de la peruanidad y la afirmación de un Perú libre e independiente". (Forgues, 1989. p. 270).

El valor cultural que refleja la obra literaria, está representado también por las canciones religiosas, su lenguaje, que conforman la ideología del lugar y época cultural del mundo andino:

“Empecé a rezar al yayayku... El rumor se hizo másintenso yelevó la voz: “yayayku, hamak'pachapi kak"...

Oí, de repente, otros gritos, mientras concluía la oración. Me acerqué a la puerta. La abrí y salí al corredor. De allí escuché mejor las voces.

- ¡Fuera peste! jway jiebre! ¡waaay...!

- ¡Ripuy, ripuy! ¡kañask'aykin! Waaay... (“ivete, vete, he de quemarte!”).

Lejos ya de la plaza, desde las calles, apostrofaban a la gente, la amenazaban, Las mujeres empezaron a cantar. Improvisaban la letra con la melodía funeraria de los entierros: 
Educa UMCH. Revista sobre Educación y Sociedad, 2020, 1(16), 5-2211 1 https://doi.org/10.15366/Educa UMCH2019.17.3.001

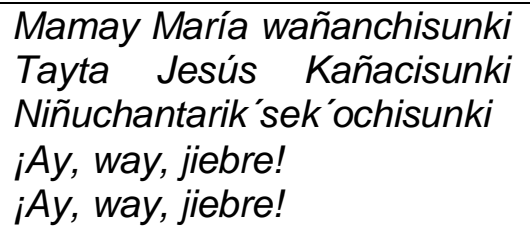

Seguirían cantando hasta la salida del pueblo. El coro se aleja, se desprendía de mí" (Arguedas, 1983. p. 201).

\section{El valor ético-moral en Los ríos profundos}

El valor ético aparece en todos los actos de la vida, es la vida entera y consistente en elegir un valor superior, sin dañar a otro superior a él, por encima de un valor inferior.

Lo ética como disciplina filosófica está referida a la conducta humana que se regula de acuerdo con dos polos valorativos: lo bueno y lo malo; el bien y el mal; lo honesto y deshonesto; lo justo y lo injusto; lo honrado y lo no honrado; lo correcto e incorrecto:

"Infundia respeto, a pesar de su anticuada y sucia apariencia. Las personas principales del Cuzco lo saludaban seriamente. Llevaba siempre un bastón con puño de oro; su sombrero de angosta ala, le daba un poco de sombra sobre la frente. Era incómodo acompañarlo, porque se arrodillaba frente a todas las iglesias y capillas y se quitaba el sombrero en forma llamativa cuando saludaba a los frailes.

Mi padre lo odiaba. Habíatrabajadocomo escribiente en las haciendas del viejo. "Desde las cumbres grita, con voz de condenado, advirtiendo a sus indios que él está en todas partes. Almacena las frutas de las huertas, y las deja pudrir; cree que valen muy poco para traerlas a vender al Cuzco o llevarlas a Abancay y que cuestan demasiado para dejárselas a los colonos. ¡Irá al infierno!”, decía de él mi padre”. Eran parientes, y se odiaban”. (Arguedas, 1983. p. 11).

El término ética está vinculado al término moral derivada del latín mores que significa igualmente "costumbre".

Por todo esto podemos decir que la moral se refiere al hecho de la conducta humana dentro de un cauce orillado por lo bueno y lo malo. Es la moralidad de un determinado grupo social, de una colectividad en una etapa histórica e inclusive, de una persona cualquiera:

"Cierta vez llegamos a un pueblo cuyos vecinos principales odian a los forasteros. El pueblo es grande y con pocos indios.

...Yo abandoné ese pueblo cuando los indios velaban sucruz enmedio delaplaza. 
Educa UMCH. Revista sobre Educación y Sociedad, 2020, 1(16), 5-221 2 https://doi.org/10.15366/Educa UMCH2019.17.3.001

Se habían reunido con sus mujeres, alumbrándose con lámparas y pequeñas fogatas. Era pasada la medianoche. Clavé en las esquinas unos carteles en que me despedía de los vecinos del pueblo, los maldecía. Salí a pie, hacía Huancayo.

En ese pueblo quisieron matarnos de hambre; apostaron un celador en cada esquina de nuestra casa para amenazar a los litigantes que iban al estudio de mi padre; odiaban a los forasteros como a las bandas de langostas. Mi padre viajaría en un camión, al amanecer; yo salí a pie de noche...".(Arguedas, 1983. p. 29).

Hay pues, una última relación entre ética y moral; se teoriza sobre hechos; aunque ambos términos son usados como equivalentes cuando se hace referencia a la disciplina se la enuncia como ética, pero cuando se señala como referencia, principio, normas de vida en sociedad, es decir la conducta de los hombres, se le enuncia como moral. De ellos se deduce que la moral apareció antes que la ética.

Entre ambos hay equivalencia, sucediendo algo semejante a lo que acontece con los términos oír y escuchar, ver y mirar que son diferentes al efectuar un análisis fino, y equivalente en su uso cotidiano.

Como vemos Arguedas nos muestra en el pasaje de su obra, que la Moral es una de las formas de la conciencia social en la que se reflejan y se fijan las cualidades "éticas" de la realidad social, la realidad de los pueblos andinos.

\section{El valor filosófico en Los ríos profundos.}

A través de este valor se estimula la reflexión y se busca las causas, como el ser de la vida, la muerte, el amor, la guerra, la incomunicación humana y otros. Además, desarrolla en las personas la capacidad de pensar y la formación filosófica. Este valor se encuentra en la obra literaria de Los ríos profundos, en las que el autor, José María Arguedas, nos muestra grandes ideas como, por ejemplo:

“-Padre -le dije-, me han avisado que la fiebre está grasando en la otra banda ¿Ud. sabe?

- ¿Qué? -preguntó el padre.

-La fiebre, padre; el tifus. Está grasando en Ninabamba; dicen que está bajando a las otras haciendas. Los colonos ya están comiendo los piojos de los muertos. Así es...

“'Está grasando la fiebre!”la noticia resonaba en toda la materia deque estoy hecho. Yo había visto morir con la peste, a cientos, en dos pueblos; en Querobamba y Sañayca. En aquellos días sentía terror cuando alguna mosca caminaba sobre mi cuerpo, o cuando caían, colgándose de los techos o de los arbustos, las arañas...

-Sí que se mueran los del otro lado no más. Como perros -replicó el Chipro.

-Tú has dicho que se están comiendo ya a los piojos de los muertos.

¿Qué es eso, hermanito?, ¿Qué es eso?

- ¿Saben, hermanos, que el piojo lleva la fiebre?...

Entréal angosto pasadizo. Lleguéal pequeño patio donde guardaban la leña ... la puerta del cuartucho donde dormía la opa estaba entreabierta.

La empujé. Me miró la cocinera. 
Educa UMCH. Revista sobre Educación y Sociedad, 2020, 1(16), 5-2213 https://doi.org/10.15366/Educa UMCH2019.17.3.001

Sobre unos pellejos descansaba el cuerpo de la opa. Me acerqué.

Le vi el rostro a la enferma. Le vi los cabellos, de cerca y la camisa mugrienta que le cubría el pecho, hasta el cuello.

En los cabellos y en la camisa de la opa pululaban los piojos; andaban lentamente, se colgaban de cada hilo de su cabellera, de los que caían hasta el rostro y la frente; en los bordes de la camisa y en la costura, los veía en filas, avanzando unos tras otros, hasta el infinito mundo.

- ¿Iman? ¿Iman? -preguntaba la cocinera.

-Tranquilízate; sal a la puerta; de allí reza. Se está muriendo -le dije. Ella lo sabía. Se arrodilló y empezó a rezar el Padre nuestro en quechua: "A esta criatura que ha sufrido recógela, Gran Señor- ¡Ha sufrido! ¡Ahora le pondrás luz en su mente, la harás ángel y la harás cantar en tu gloria! Gran Señor... (Arguedas, 1983. p. 182).

En este párrafo, José María Arguedas, a través de Ernesto, nos muestra la peste, la fiebre ocasionada por los piojos de la pobreza, que ocasiona la muerte de los colonos y de la opa Marcelina. En donde se muestra esa profunda humanidad, resultando viva aquí y ahora en cada conflicto del hombre de hoy que lo enfrenta a desarrollar igual fortaleza de espíritu frente a la vida y a la muerte, encomendando el alma a Dios.

\section{El valor recreativo en Los ríos profundos}

La novela Los ríos profundos presenta la función del deleite, como la recreación que presenta en sus diálogos que permite el entendimiento de la cultura nacional peruana, complementada por huaynos como aparece a lo largo de la novela. Los jarahuis y los huaynos que son canciones que cantan los indígenas quechuas, y que son manifestaciones reideras y que nos llevan a entretenernos, en las actitudes típicas de la sociedad, perteneciente al folklore y al estilo de vida propias del pueblo andino.

“- ¿Tú quieres, muchacho? - me preguntó un mestizo que parecía ser un cargador del mercado.

-Sí quiero -le contesté

Me alcanzó una jarra pesada; levanté y sostuve en alto con mucha dificultad, para beber, mientras el mestizo y los de su grupo se reían. La chicha era fuerte y sentí que me abrigaba.

- ¡Buena, muchacho! ¡Caray! ¡Caray, guapo! ¡Adentro, adentro consuelo! -gritaba mi invitante oyendo los largos tragos que tomaba.

- ¿Y por qué es la fiesta, don? -le pregunté.

- ¡Ja caraya! -dijo. Y lanzó una carcajada. -La mujer, pues, ha hecho correr a los guardias. La salinera, pues han agarrado. ¡Viva doña Felipa! 
Educa UMCH. Revista sobre Educación y Sociedad, 2020, 1(16), 5-2211 4 https://doi.org/10.15366/Educa UMCH2019.17.3.001

Y empezó a cantar un huayno cómico que yo conocía; pero la letra, improvisada por él en ese instante, era un insulto a los gendarmes y al salinero. Todos los del grupo formaron un coro. Alternaban cada estrofa con largas carcajadas... se miraban y volvían a reírse:

(Arguedas JM. 1983.p. 94).

\begin{tabular}{|l|c|}
\hline Sodaduchapa riflink'a & El rifle del soldadito \\
Tok'romantas kask'a & había sido de huesos del cactus, \\
Chaysi chaysi & por eso, por eso, \\
Yank'a yank'a tok'an & truena inútilmente, \\
Chaysi chaysi & por eso, por eso, \\
Yank'a yank'a tok'yan & truena inútilmente. \\
Manas manas wayk'ey, & No, no, hermano, \\
riflinchu tok'ro & no es el rifle, \\
alma rurullansi & es el alma del soldadito \\
Tok'ro tok'ro kask'a & de leña inservible. \\
Salineropa revolverchank'a & El revólver del salinero \\
Llama akawansi & estaba cargado \\
Asmask'a kask'a & Con excremento de llama, \\
polvorañantak' & Y en vez de pólvora. \\
Mula salinerok' & y en vez de pólvora \\
Asnay asnay supin. & pedo de mula salinera \\
& \\
\hline
\end{tabular}




\section{Conclusiones}

Los valores literarios como disciplina buscan la utilidad y posibilidad de penetrar al estudio ordenado y profundo de la obra literaria, que está al servicio de la enseñanzaaprendizaje para desarrollar las habilidades lingüísticas en los estudiantes.

Realmente el reconocimiento de los valores literarios nos lleva al conocimiento de la vida, al perfeccionamiento humano y al desarrollo de los ideales. Así mismo al desarrollo del altruismo, la libertad, la justicia, el amor, la vida, la muerte, etc.

Arguedas escribió la novela poemática, Los ríos profundos con sencillez, amor y fidelidad a la raza indígena. En donde los desposeídos, los campesinos solo pueden vivir feliz en el mundo andino. Allí trabajan mancomunada y comunitariamente; pero cuando están fuera de su habitad, los comuneros viven explotados por los poderosos. Arguedas plantea valorar y defender a los campesinos; debido a que pasó su infancia y parte de su adolescencia con los indios, y él mismo sufrió el abuso y el maltrato de los terratenientes de ese tiempo.

Los ríos profundos constituyen una de las novelas clásicas de la Literatura Latinoamericana y Universal, por su calidad y vitalidad literaria y por los valores literarios de contenidos: estético, humano, social, cultural, ético-moral, filosófico, recreativo, etc.

La valoración de la obra de Arguedas se inició en un proceso lento, desde que ganó en Lima el premio Nacional "Fomento a la cultura Ricardo Palma" en 1959 y fue finalista en los Estados Unidos, logrando obtener el premio William Faulkner en 1963. A partir de ese entonces, el libro de Los ríos profundos se publicó y se tradujo en varios idiomas, y creció el interés por su lectura y el desarrollo de la crítica literaria, como mencionó Vargas Llosa, M.

Arguedas muestra su genialidad en la elaboración de Los ríos profundos, como la novela poemática de tenso lirismo, donde existe la presencia de elementos simbólicos y el empleo magistral de "El realismo mágico" o lo "real maravilloso" desde Carpentier.

Los ríos profundos señalan la continuidad y la autenticidad de los valores del mundo quechua, una de ellas es el retorno a su tierra natal, a su comunidad, la vuelta a la contemplación del río, que le ayuda al personaje de Ernesto a salir de su soledad, de su marginación, de su desarraigo. El río cristalino tiene un poder liberador de los pensamientos perturbables. Este río silencioso y profundo pasa en paz, llevando salud en sus aguas, pasa prudentemente sin alborotar sus aguas, transcurre como los hombres sabios silenciosamente.

Finalmente, Los ríos profundos es una novela de gran calidad artística, nos trae un mensaje de amor, de amistad, de hogar, de educación. En este escenario el padre se preocupa por el personaje de Ernesto, por su hijo huérfano de madre, en un ambiente de un drama ético y cultural en medio de una sociedad llena de contradicciones, y para evadirse de este desasosiego padre e hijo buscan alegrarse en la música andina, siendo de preferencia los huaynos de diferentes zonas del Perú. Asimismo, de los valores andinos: la solidaridad y fraternidad. Que les permite mantenerse en su terruño, es como volver a los brazos de su madre ausente y a la pachamama. 
Educa UMCH. Revista sobre Educación y Sociedad, 2020, 1(16), 5-2216 https://doi.org/10.15366/Educa UMCH2019.17.3.001

\section{Referencias}

Aibar R.E. (1992). Identidad y resistencia cultural en las obras de José María Arguedas. Lima. Perú: Universidad Católica del Perú.

Arguedas J.M. (1983). Los ríos profundos -obras completas- Lima. Perú: Horizonte.

Castro K.S. (1973). El mundo mágico de José María Arguedas. Lima. Perú: IEP.

Cortés G. (1993). Análisis de Los ríos profundos. Bogotá-Colombia: Círculo de lectores.

Cornejo P.A. (1997). Los universos narrativos de José María Arguedas. Lima: Horizonte.

Escajadillo T. (1994). La narrativa indigenista peruana. Lima. Perú: Amaru.

Espinoza R.M. (1992). Análisis e interpretación de textos literarios. Lima. Perú: San Marcos.

Forgues R. (1989). Arguedas. Del pensamiento dialéctico al pensamiento trágico. Lima. Perú: Horizonte.

Glaudieu M. (2004). Estructura de Los ríos profundos de José María Arguedas. Lima. Perú: Universidad San Martín.

Larco J. (1976). José María Arguedas. La Habana. Cuba: Casa de las Amèricas.

Montoya R. (1991). José María Arguedas. 20 años después. Lima: UNMSM.

Morreros V. (1913). Max Scheler. Fundador de la ética material de los valores. Madrid. España: Planeta.

Rowe W. (1996). Ensayos Arguedianos. Lima. Perú: UNMSM.

Salazar I. (2004). Los ríos profundos y los poderes del lenguaje. Lima: Universidad de San Martin.

Urrello A. (1974). José María Arguedas. Lima. Perú: Juan Mejía Baca.

Vargas Ll. (1996). La utopía Arcaica, José María Arguedas y las ficciones del Indigenismo. México. Fondo Cultura Económica.

Victorio J. (1999). Tecnología de la enseñanza-aprendizaje del lenguaje y la literatura. Lima. Perú: Alma Mater. 